\title{
oints
}

$\sqrt{2}$

\section{Calcific tendinitis of the shoulder}

\author{
ANGELO DE CARLI ${ }^{1}$, FERDINANDO PULCINELLI ${ }^{1}$, GIACOMO DELLE ROSE ${ }^{2}$ \\ DARIO PITINO ${ }^{3}$, ANDREA FERRETTI ${ }^{1}$ \\ 1 II Faculty of Medicine and Surgery, "Sapienza" University of Rome, S. Andrea University Hospital, Rome, Italy \\ ${ }^{2}$ Shoulder and Elbow Unit, Humanitas Research Hospital, Rozzano, Milan, Italy \\ ${ }^{3}$ Department of Orthopaedics, University of Catania, Vittorio Emanuele Hospital, Catania, Italy
}

\begin{abstract}
Calcific tendinitis is a common disease that predominantly affects individuals aged between 40 and 60 years. Women seem to be more affected than men. Various factors have been suggested to play a role in this condition, such as abnormal activity of the thyroid gland, metabolic diseases (e.g. diabetes), and genetic predisposition. Various etiological hypotheses have been advanced: the degenerative and multiphasic theories are the two most accredited ones. Clinically, calcific tendinitis is characterized by severe, disabling pain which occurs spontaneously, usually in the morning. There can be concomitant stiffness, giving rise to a frozen shoulder-like clinical picture. Conventional radiography of the shoulder is the most appropriate imaging approach. Most cases resolve spontaneously. Many conservative treatments have been reported in the literature, showing varying levels of evidence of efficacy. Arthroscopic surgery is the orthopedic specialist's last option. It is to be noted that post-surgical pain can persist for many weeks after the operation. Finally, it is important not to forget the variant characterized by osteolytic involvement of the greater tuberosity, which has been associated with a worse clinical outcome, both after conservative treatment and after surgery.
\end{abstract}

Corresponding Author:

Angelo De Carli, MD

II Faculty of Medicine and Surgery, "Sapienza” University,

S. Andrea University Hospital

Via di Grottarossa, 1035/1039, 00189 Rome, Italy

Phone: +3906 33775818

E-mail: angelo.decarli@gmail.com
Key words: arthroscopy, calcific tendinitis, calcium deposit, rotator cuff, shoulder.

\section{Introduction}

Calcific tendinitis of the shoulder is an acute or chronic painful condition due to the presence of calcific deposits inside or around the tendons of the rotator cuff; more specifically, it is caused by the deposition of calcium hydroxyapatite crystals commonly within the supraspinatus and infraspinatus tendons (1).

Calcific tendinitis predominantly affects individuals aged between 40 and 60 years. Women seem to be more affected than men. Perhaps surprisingly, the incidence of this disease is not higher either in individuals who do heavy duty work involving the upper limbs, or in overhead athletes.

In 1872, Duplay (2) was the first to describe calcific tendinitis of the shoulder; he defined this arthropathy as "painful periarthritis of the shoulder". In 1934, Codman (3) realized that the calcific deposits, which initially were thought to be inside the subacromial bursa, actually developed either inside or near the tendons. Bosworth (4), in a large series of patients, recorded a $2.7 \%$ incidence of calcific tendinitis of the shoulder. The pathology was asymptomatic in 35\% of the cases and supraspinatus tendon involvement was found in $51 \%$.

Loew et al. (5) described the most commonly affected sites, and also reported the prevalence rates of involvement of the different rotator cuff tendons (Tab. 1). 
Table 1. Prevalence rates of involvement of the different rotator cuff tendons (5).

\begin{tabular}{ll}
\hline & Prevalence (\%) \\
\hline Supraspinatus tendon & $63 \%$ \\
Supraspinatus and subscapularis tendons & $20 \%$ \\
Subscapularis tendon & $3 \%$ \\
Infraspinatus tendon & $7 \%$ \\
Subacromial bursa & $7 \%$ \\
\hline
\end{tabular}

\section{Etiology}

Calcific tendinitis is a multifocal, cell-mediated disease in which metaplastic transformation of tenocytes into chondrocytes induces subsequent calcification inside the tendon. This is followed by phagocytosis of the metaplastic areas in the tendons by multinucleated giant cells. Ultimately, the tendon remodels and reforms normal tendon.

The etiology of calcific tendinopathy is still difficult to understand. Rathbun and Macnab (6) described ischemia of the rotator cuff tissue during calcific tendinitis. Booth and Marvel (7) described degeneration of the tissue as a result of ischemic injury. Riley et al. (8) described a metabolic disorder associated with ischemic injury and degeneration of rotator cuff tissue.

The two most accredited etiological theories are the degenerative theory, proposed by Refior et al. (9), which highlights similarities with degenerative lesions of the rotator cuff, and the multiphasic disease theory, proposed by Uhthoff and Loehr (10), which suggests that deposition of calcium in the tissues is followed by spontaneous resorption of the calcific deposit (a cellmediated process).

Other theories introduced in recent years hypothesize involvement of other factors, such as: chemical factors responsible for inducing the calcium deposition, cell proliferation, the production of anti-inflammatory agents, abnormal activity of the thyroid gland, metabolic diseases (e.g. diabetes), and genetic predisposition to the formation of calcific deposits (11).

Uhthoff and Loehr (10) described a three-phase process: pre-calcific, calcific (divided into three subphases: formative, resting and resorptive), and post-calcific (Fig. 1). Gosens and Hoftsee (12) identified four phases (pre-calcific, formative, resorptive and recovery). Both these models identified a pre-calcific phase, cha-

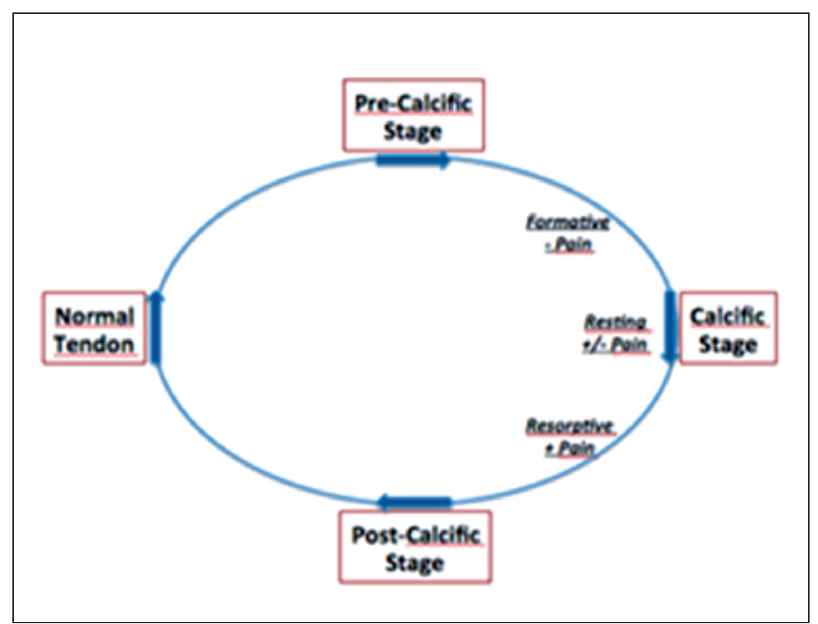

Fig. 1. Cyclic theoretical model proposed by Uhthoff and Loer (10).

racterized by a fibrocartilaginous metaplasia; a calcification phase, characterized by formation of the calcium deposit; a stable phase, with the presence of "mature" calcifications; and a resorptive phase. The latter phase, of varying duration, includes a period of spontaneous resorption during which there is both neoangiogenesis, beginning at the margin of the deposit, and infiltration of phagocytes.

\section{Clinical presentation}

Patients with calcific tendinitis typically present severe, disabling pain which occurs spontaneously, usually in the morning. There can be concomitant stiffness, giving rise to a frozen shoulder-like clinical picture. Patients may report anterior pain, located near the bicipital groove (in which the long head of the biceps tendon runs), or posterior pain, located below the spine of the scapula. There may be concomitant contracture of the trapezius and rhomboids.

\section{Imaging}

The evaluation of calcific tendinitis is based mainly on imaging studies, such as: $\mathrm{x}$-rays, ultrasound (US) and magnetic resonance (MR) of the shoulder, which make it possible to detect and classify the pathology (Tab. 2). 
Table 2. Imaging classifications of calcific tendinitis of the shoulder.

\begin{tabular}{ll}
\hline Author & Classification \\
\hline Bosworth (4) & Small $<0.5 \mathrm{~mm}$ \\
& Medium $0.5-1.5 \mathrm{~mm}$ \\
& Large $>1.5 \mathrm{~mm}$ \\
\hline DePalma and Kruper (13) & Fluffy (Acute) \\
& Dense (Subacute or Chronic) \\
\hline Patte and Goutallier (14) & Type I: Sharp and dense \\
& Type II: Blunt and dense \\
& Type III: Sharp and translucent \\
& Type IV: Blunt and translucent \\
\hline Gärtner and Simons (15) & Type I: Sharply outlined and dense \\
& Type II: Sharply outlined and inhomogeneous calcification or homogeneous \\
& calcification with no defined border \\
& Type III: Cloudy and transparent calcification \\
\hline Farin et al. (16) & Type I: Large deposit in the tendon or the bursa \\
& Type II: Many small calcifications \\
& Type III: A few small calcifications \\
\hline Loewet al. (17) & Type A: compact and homogeneous one-part structure, clearly defined outline \\
& Type B: subdivided homogeneous structure, clearly defined outline \\
& Type C: diffuse area of low-signal intensity, no defined outline in the tendon \\
\hline
\end{tabular}

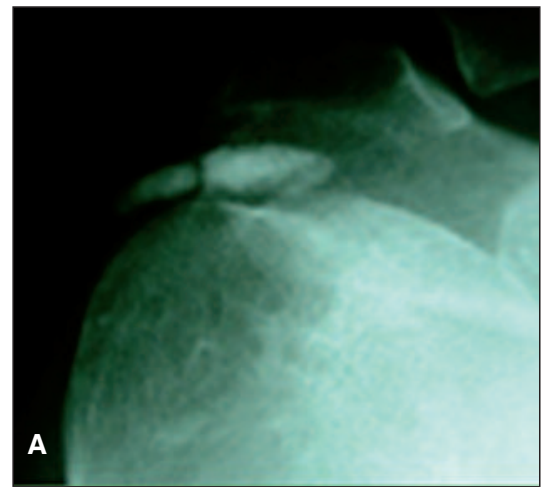

Fig. 2. Dense (A) and fluffy (B) calcification.

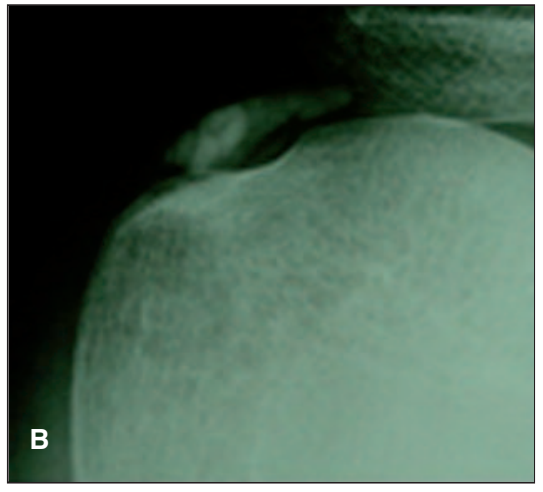

Fig. 3. US-scan image of calcific tendinitis.

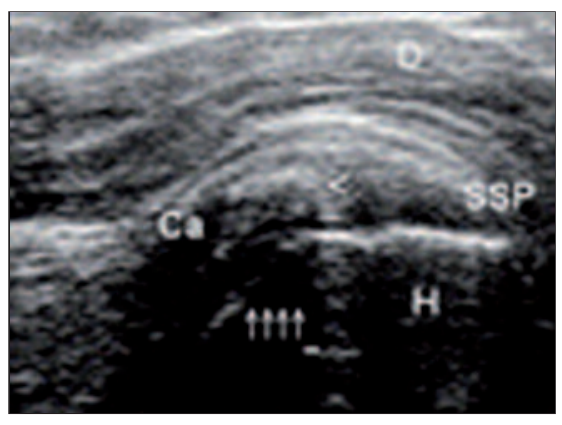

Bosworth (4) proposed a classification based on the dimensions of the calcification on $\mathrm{x}$-ray evaluation. DePalma and Kruper (13) proposed a radiographic classification, correlating calcification morphology with disease phase (acute, subacute, chronic) (Fig. 2). Patte and Goutallier (14) and Gärtner and Simons (15) proposed a radiographic classification based on the morphological appearance of the calcification, identifying different types. Farin and Jaroma (16) proposed a classification based on the location and appearance of the calcification evaluated with US (Fig. 3). Loew et al. (17) proposed the first MR classification based on the morphological appearance of the calcific tendinitis (Fig. 4).

\section{Treatment}

Many different options are reported in the literature for treating calcific tendinopathy of the rotator cuff. Treatment of this condition can be conservative or surgical. 


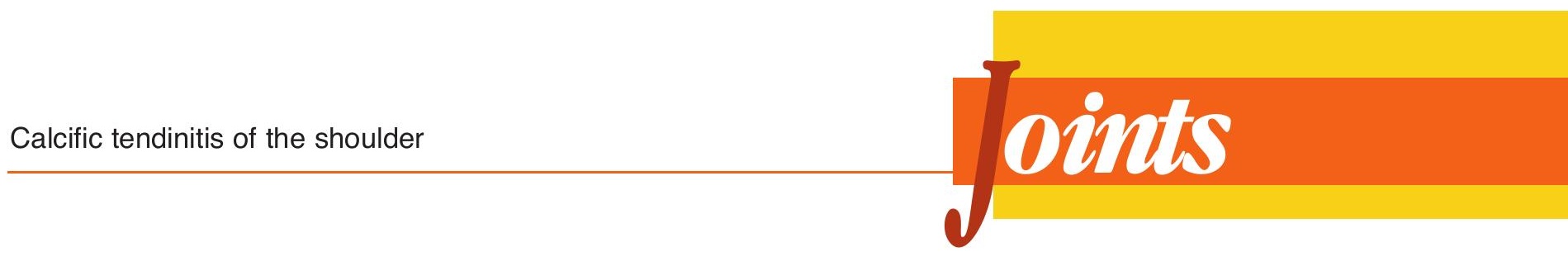

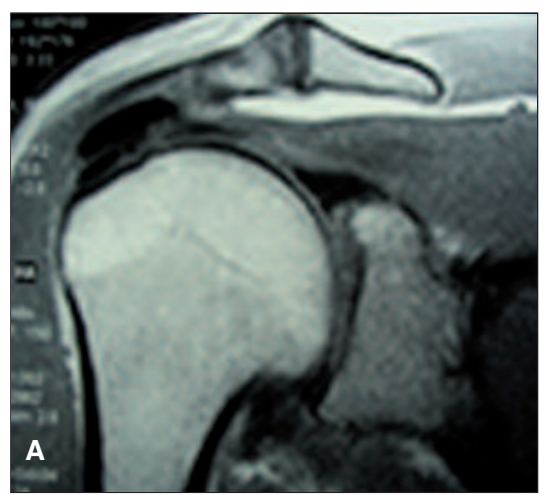

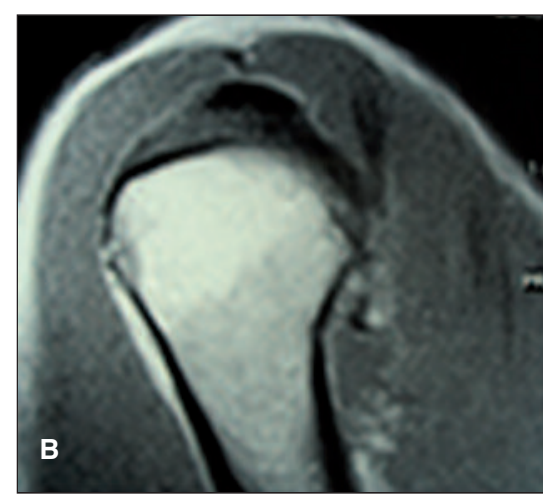

Fig. 4. MR coronal (A) and sagittal oblique (B) scans of calcific tendinitis.
$78.1 \%$ of shoulders at one year after aspiration and lavage.

Recently, de Witte et al. (26) described the differences observed between a group of patients treated with USguided percutaneous needling and lavage and a group of patients treated with simple subacromial injection of corticosteroid; at one year after treatment the group of patients treated with needling showed better recovery of shoulder function (Constant score: 86/100) with respect to those treated with steroid injection; furthermore,

\section{Iontophoresis with acetic acid}

The first application of this technique in orthopedics was described by Beutl and Clementshitsch (18). Iontophoresis involves the use of an electrode inserted in a sponge which increases the absorption, through the skin, of a drug, in this case acetic acid. The use of acetic acid is based on the concept that the hydroxyapatite crystals are soluble in solutions with an acid $\mathrm{pH}$. Leduc et al. (19) compared the results obtained in patients treated with physical therapy (PT) and iontophoresis with acetic acid with those obtained in patients treated with PT and iontophoresis with placebo. The study failed to provide clear significant results in support of the use of acetic acid iontophoresis.

\section{Steroid injections and percutaneous needling}

Subacromial steroid injection and percutaneous needling are treatments often applied in rotator cuff calcific tendinopathy (20-24). Subacromial steroid injections have several advantages: they are inexpensive and relatively easy to perform, and carry a low risk of complications.

Percutaneous needling is more invasive, involving the use of a needle for the infiltration of lidocaine and the aspiration of the calcific material. The procedure is performed under US guidance.

Galletti et al. (22), in a series of patients followed up for around two years, reported resolution of the symptoms after percutaneous needling in nearly $90 \%$, and complete radiographic resolution of the calcific tendinopathy in 54\%, while del Cura et al. (25) reported complete resolution of calcific tendinopathy in complete resorption occured more frequently in the patients treated with needling (13 out of 23 patients) than in those treated with corticosteroid injection (6 out of 25 patients).

\section{Extra-corporeal shock wave therapy}

Several studies have demonstrated the efficacy of extracorporeal shock wave therapy (ESWT), either radial (rESWT) or focal (fESWT), in rotator cuff calcific tendinopathy $(27,28)$.

ESWT is based on the use of single pressure pulses, or shock waves. By means of US or radiographic guidance, these are focused on the calcification. The use of rESWT has been reported to give satisfactory results, but to date there are no level-1 reports in the literature. Lee et al. (29), in a systematic review, reported moderate evidence supporting the use of fESWT.

Cosentino et al. (30) showed that ESWT led to decreased pain and increased shoulder function; complete resorption of the calcification was reported in $31 \%$ of their cases. calcifications in $86.6 \%$ of their treated patients and partial resorption in $13.4 \%$, but their data there were not confirmed by subsequent studies, like that of Hsu et al. (32), who reported a $21.2 \%$ frequency of complete resorption with improved shoulder function and a decrease in pain in patients treated with ESWT $\left(0.55 \mathrm{~mJ} / \mathrm{mm}^{2} 1000\right.$ pulses $)$.

Krasny et al. (33) reported that ESWT in association with needling led to a higher frequency of disappearance $(60 \%)$ of the calcification compared with ESWT alone (35\%).
Cacchio et al. (31) reported complete resorption of 
The energy level used does not influence the frequency of resorption of the calcification, as demonstrated by Ioppolo et al. (34). This finding probably supports the theory that changes in the microcirculation are the real effectors of resorption of rotator cuff calcification.

\section{Platelet-rich plasma}

Seijas et al. (35) reported the case of a 44-year-old woman in whom they used PRP injections (three treatments administered at two-week intervals). All previous treatments in this patient had failed. Her symptoms regressed within six weeks and the benefit was maintained at one year.

\section{Surgical treatment}

Approximately $10 \%$ of patients are resistant to conservative treatment and therefore need surgery to remove the calcium deposits (36). Surgery is indicated in patients with severe symptoms persisting for more than six months (36).

Two types of surgical treatment are available: open surgery $(37,38)$ and arthroscopic treatment $(39)$.

The arthroscopic technique consists of an articular stage and a subacromial stage. After a glenohumeral inspection, the subacromial stage is performed through the posterior and lateral portals. After bursal debridement, the calcium deposits are localized by percutaneous needling (Fig. 5). Residual calcification is than excised using a resector and curettes.

Recovery after arthroscopic treatment is variable and

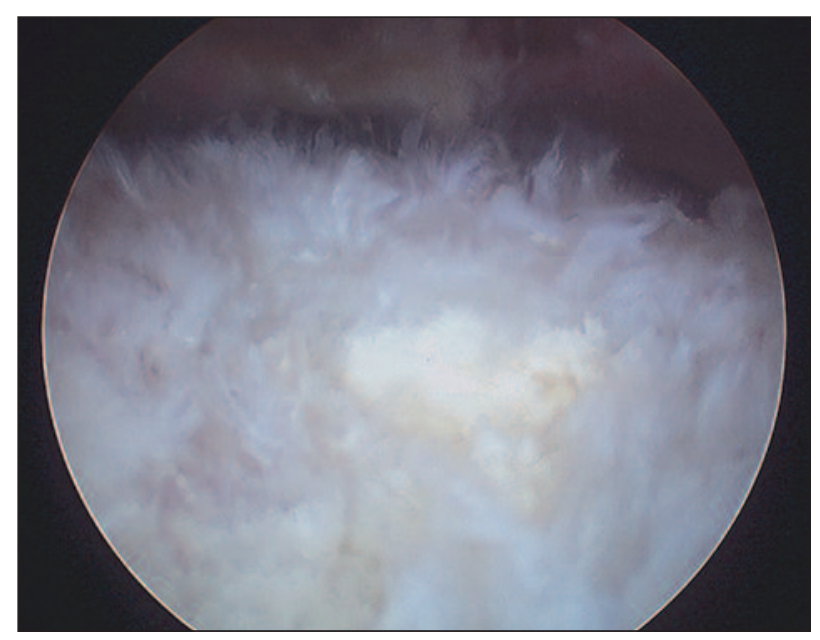

Fig. 5. Arthroscopic view of calcium deposits. the post-operative recovery process can be lengthy and painful (even taking as long as 28 months) (40).

Porcellini et al. (41) considered the question of whether or not to suture the tendon after removal of the calcific deposits: in the authors' view suturing is indicated in the presence of a complete or partial lesion larger than $1 \mathrm{~cm}$, and not indicated in the presence of a partial lesion of less than $1 \mathrm{~cm}$.

The importance of removing all of the calcium deposit is extensively debated in literature. Porcellini et al. (41), studying 58 patients followed up for three years, highlighted the importance of removing all the calcific deposit, finding better shoulder function at follow-up in patients in whom complete removal of the calcifications had been achieved.

Recently, Maier et al. (42) studied 93 patients with mean follow-up of 37.3 months. They showed that it is not important to remove all the calcific deposit; residual calcification was resorbed within 6-12 months of the surgical treatment and there were no significant differences in outcomes between patients with and those without complete removal of calcific deposits.

Porcellini et al. (43) described an unusual "variant" of calcific tendinitis characterized by osteolytic involvement of the greater tuberosity. The authors presented this tuberosity osteolysis as a distinct form of calcific tendonitis associated with a worse clinical outcome, both after conservative treatment and after arthroscopic removal of the calcific deposit.

The importance of acromioplasty is also debated in literature. Molé et al. (44) stressed the importance of acromioplasty in patients with small calcific deposits. Jacobs and Debeer (45) did not find statistical differences between patients treated only with removal of calcific deposits, and those treated with removal of calcification in association with acromioplasty. Balke et al. (46) studied the acromial index in a group of patients with calcific tendinitis and a group with subacromial impingement and the results were similar in the two groups.

\section{Conclusions}

The formation and resorption of calcifications in calcific tendinitis of the shoulder are cell-mediated, often multifocal, processes. The condition often 
resolves spontaneously, but it can become chronic. Iontophoresis with acetic acid is obsolete, and it is not indicated for rotator cuff calcific tendinopathy. Steroid injections combined with physiotherapy could be an option in conservative treatment. If the symptoms persist it is possible to use percutaneous needling or ESWT.

Approximately $10 \%$ of patients are resistant to conservative treatment, and in these cases surgery is required to remove the calcium deposit. Arthroscopic treatment is the gold standard of surgical treatment, but two questions remain open: whether it is necessary to remove all the calcific deposit and whether acromioplasty is necessary.

\section{References}

1. Speed CA, Hazleman BL. Calcific tendinitis of the shoulder. N Engl J Med. 1999;340:1582-1584.

2. Duplay S. De la peri-arthrite scapulo-humerale et des raideurs de l'epaule qui en sont la consequence. Arch Gen Med. 1872;20:513-542.

3. Codman EA. The Shoulder: Rupture of the Supraspinatus Tendon and Other Lesions in or about the Subacromial Bursa. Boston: Thomas Todd Co.1934.

4. Bosworth BM. Calcium deposits in the shoulder and subacromial bursitis: a survey of 12122 shoulders. JAMA. 1941; 116:2477-2482.

5. Loew M, Jurgowski W, Mau HC, et al. Treatment of calcifying tendinitis of rotator cuff by extracorporeal shock waves: A preliminary report. J Shoulder Elbow Surg. 1995;4:101-106.

6. Rathbun JB, Macnab I. The microvascular pattern of the rotator cuff. J Bone Joint Surg Br. 1970;52:540-553.

7. Booth RE Jr, Marvel JP Jr. Differential diagnosis of shoulder pain. Orthop Clin North Am. 1975;6:353-379.

8. Riley GP, Harrall RL, Constant CR, Chard MD, Cawston TE, Hazleman BL. Tendon degeneration and chronic shoulder pain: changes in the collagen composition of the human rotator cuff tendons in rotator cuff tendinitis. Ann Rheum Dis. 1994;53:359-366.

9. Refior H, Krödel A, Melzer C. Examinations of the pathology of the rotator cuff. Arch Orthop Trauma Surg. 1987;106:301308.

10. Uhthoff HK, Loehr JW. Calcific tendinopathy of the rotator cuff: pathogenesis, diagnosis and management. J Am Acad Orthop Surg. 1997;5:183-191.

11. Harvie P, Pollard TC, Carr AJ. Calcific tendinitis: natural history and association with endocrine disorders. J Shoulder Elbow Surg. 2007;16:169-173.

12. Gosens T, Hofstee DJ. Calcifying tendinitis of the shoulder: advances in imaging and management. Curr Rheum Rep. 2009;11:129-134.

13. DePalma AF, Kruper JS. Long term study of shoulder joints afflicted and treated for calcific tendinitis. Clin Orthop. 1961;20:61-72.

14. Patte CF, Goutallier D. Calcifications. Rev Chir Orthop. 1988;74:277-278.
15. Gärtner J, Simons B. Analysis of calcific deposits in calcifying tendinitis. Clin Orthop Relat Res. 1990;(254):111-120.

16. Farin PU, Jaroma H. Sonographic findings of rotator cuff calcifications. J Ultrasound Med. 1995;14:7-14.

17. Loew M, Sabo D, Wehrle M, et al. Relationship between calcifying tendinitis and subacromial impingement: a prospective radiography and magnetic resonance imaging study. J Shoulder Elbow Surg. 1996;5:314-319.

18. Beutl O, Clementschitsch A. Iontophoresis in therapy of humeroscapular periarthritis and epicondylitis of the humerus. Wien Med Wochenschr. 1952;102:36.

19. Leduc BE, Caya J, Tremblay S, et al. Treatment of calcifying tendinitis of the shoulder by acetic acid iontophoresis: a double-blind randomized controlled trial. Arch Phys Med Rehabil. 2003;84:1523-1527.

20. Arroll B, Goodyear-Smith F. Corticosteroid injections for painful shoulder: a meta-analysis. Br J Gen Pract. 2005;55: 224-228.

21. Farin PU, Räsänen $H$, Jaroma $H$, et al. Rotator cuff calcifications: treatment with ultrasound-guided percutaneous needle aspiration and lavage. Skeletal Radiol. 1996;25:551-554.

22. Galletti S, Magnani M, Rotini R, et al. The echo-guided treatment of calcific tendinitis of the shoulder. Chir Organi Mov. 2004;89:319-323.

23. Koester MC, Dunn WR, Kuhn JE, et al. The efficacy of subacromial corticosteroid injection in the treatment of rotator cuff disease: a systematic review. J Am Acad Orthop Surg. 2007;15:3-11.

24. Serafini G, Sconfienza LM, Lacelli F, et al. Rotator cuff calcific tendinitis: short-term and 10-year outcomes after twoneedle US-guided percutaneous treatment. Non randomized controlled trial. Radiology. 2009;252:157-164.

25. del Cura JL, Torre I, Zabala R, et al. Sonographically guided percutaneous needle lavage in calcific tendinitis of the shoulder: short- and long-term results. AJR Am J Roentgenol. 2007;189:W128-134.

26. de Witte PB, Selten JW, Navas A, et al. Calcific tendinitis of the rotator cuff: randomized controlled trial of ultrasoundguided needling and lavage versus subacromial corticosteroids. Am J Sports Med. 2013;41:1665.

27. Mouzopoulos G, Stamatakos M, Mouzopoulos D, et al. Extracorporeal shock wave treatment for shoulder calcific tendonitis: a systematic review. Skeletal Radiol. 2007;36:803811.

28. Ioppolo F, Tattoli M, Di Sante L, et al. Clinical improvement and resorption of calcifications in calcific tendinitis of the shoulder after shock wave therapy at 6 months' follow-up: a systematic review and meta-analysis. Arch Phys Med Rehabil. 2013;94:1699-1706.

29. Lee SY, Cheng B, Grimmer-Somers K. The midterm effectiveness of extracorporeal shockwave therapy in the management of chronic calcific shoulder tendinitis. J Shoulder Elbow Surg. 2011; 20:845-854.

30. Cosentino R, De Stefano R, Selvi E, et al. Extracorporeal shock wave therapy for chronic calcific tendinitis of the shoulder: single blind study. Ann Rheum Dis. 2003;62:248250.

31. Cacchio A, Paoloni M, Barile A, et al. Effectiveness of radial shock-wave therapy for calcific tendinitis of the shoulder: single-blind, randomized clinical study. Phys Ther. 2006;86: 672-682.

32. Hsu CJ, Wang DY, Tseng KF, et al. Extracorporeal shock wave therapy for calcifying tendinitis of the shoulder. J Shoulder Elbow Surg. 2008;17:55-59.

33. Krasny C, Enenkel M, Aigner N, et al. Ultrasound-guided 


\section{oints}

needling combined with shock-wave therapy for the treatment of calcifying tendonitis of the shoulder. J Bone Joint Surg Br. 2005;87:501-507.

34. Ioppolo F, Tattoli M, Di Sante L, et al. Extracorporeal shockwave therapy for supraspinatus calcifying tendinitis: a randomized clinical trial comparing two different energy levels. Phys Ther. 2012;92:1376-1385.

35. Seijas R, Ares O, Alvarez P, et al. Platelet-rich plasma for calcific tendinitis of the shoulder: a case report. J Orthop Surg (Hong Kong). 2012;20:126-130.

36. Lam F, Bhatia D, Van Rooyen K, et al. Modern management of calcifying tendonitis of the shoulder. Curr Orthop. 2006;20:446-452.

37. McLaughlin HL. The selection of calcium deposits for operation; the technique and results of operation. Surg Clin North Am. 1963;43:1501-1504.

38. Neer CS II. Ed. Shoulder Reconstruction. Philadelphia: Saunders. 1990;427-33.

39. Snyder SJ, Eppley RA, Brewster S. Arthroscopic removal of subacromial calcification. J Arthroscopy. 1991;7:322.

40. Marder RA, Heiden EA, Kim S. Calcific tendonitis of the shoulder: is subacromial decompression in combination with removal of the calcific deposit beneficial? J Shoulder Elbow Surg. 2011;20: 955-960.

41. Porcellini G, Paladini P, Campi F, et al. Arthroscopic treatment of calcifying tendinitis of the shoulder: clinical and ultrasonographic follow-up findings at two to five years. J Shoulder Elbow Surg. 2004;13:503-508.

42. Maier D, Jaeger M, Izadpanah K, et al. Rotator cuff preservation in arthroscopic treatment of calcific tendinitis. Arthroscopy. 2013;29: 824-831.

43. Porcellini G, Paladini P, Campi F, et al. Osteolytic lesion of greater tuberosity in calcific tendinitis of the shoulder. J Shoulder Elbow Surg. 2009;18:210-215.

44. Molé D, Kempf JF, Gleyze P, et al. Results of endoscopic treatment of non-broken tendinopathies of the rotator cuff. 2. Calcifications of the rotator cuff. Rev Chir Orthop Reparatrice Appar Mot. 1993;79:532-541.

45. Jacobs R, Debeer P. Calcifying tendinitis of the rotator cuff: functional outcome after arthroscopic treatment. Acta Orthop Belg. 2006;72:276-281.

46. Balke M, Banerjee M, Vogler T, et al. Acromial morphology in patients with calcific tendinitis of the shoulder. Knee Surg Sports Traumatol Arthrosc. 2014;22:415-421. 